\title{
Working Optimally with Serial Sections in Glycol Methacrylate Resin
}

\section{Carlos André Espolador Leitão ${ }^{1 *}$,}

${ }^{1}$ Universidade Estadual do Sudoeste da Bahia - Departamento de Ciências Naturais, Vitória da Conquista, Bahia, Brasil

\begin{abstract}
The present work presents an optimized form for distributing serial sections in a glycol methacrylate slide set. This consists of filling the first row with sections from each slide, thus proceeding in the same way with the other rows. Therefore each slide will contain sections of three distinct sample segments.
\end{abstract}

Key words: cytology, histology, historesin, microscopy, plant anatomy, technique.

\footnotetext{
*Author for correspondence: candreel@yahoo.com.br
} 
In histology, serial sections are fundamental for understanding the three-dimensional structure of the organ or tissue analyzed under the light microscope. In paraffinembedded tissues, the obtention of serial sections is facilitated by their spontaneous strip formation during the microtome sectioning process. However, in the glycol methacrylate resin (historesin)-embedded samples, a strip is not formed during sectioning at a microtome, although it is reported the possibility of its formation by the application of Tackiwax ${ }^{\circledR}$ adhesive in the resin block ${ }^{1}$.

For historesin sections distension and settle on a histological slide, two techniques are generally adopted: 1 - The sections are left floating in a container with distilled water and they are collected with a slide. 2- Drops of distilled water are placed on the slide and each cut is distended on its specific drop ${ }^{2}$. The latter facilitates the obtention of serial sections, being probably the most used form for this purpose.

Using the Histomold ${ }^{\circledR} 6 \times 8 \mathrm{~mm}$ (Leica) mold during the inclusion step, the obtained blocks containing the samples will have the correct size to obtain sections which are comfortably accommodated in three rows of five, giving a total of 15 sections per slide (Fig. 1 A). By naming the rows as A, B, and C, and their sections as 1, 2, 3, 4 and 5, it is possible to name each section of the slide by its coordinate (eg A1, B3, C4, etc.), which facilitates annotations during slide analyzes and micrographs acquirement (Fig. $1 \mathrm{~B})$.

The most intuitive way to arrange sections of a sample on the slide set is to place them in the same sequence as they were obtained. Thus, the entire row A is filled, then B, and finally the row $\mathrm{C}$ of the first slide, thus proceeding in the same way with the others ${ }^{3}$, where the first sections are on the first slide, and the last ones on the last slide for the sample in question. Assuming that a sample is sectioned in 90 sections, it would result in a set of six slides, where the slide 1 would have sections of the segment I of the sample, slide 2 sections of segment II, and so on (Fig. 1 C, D). If all slides are submitted to the same staining, this form of sections distribution is the most coherent. Nevertheless, in the case of using several histochemical and staining techniques, the information obtained in each procedure will be limited to each sample segment correspondent to the slide in question. This condition becomes especially undesirable in longitudinal sections since that those that are correspondent to the peripheral segments of the sample would be restricted to the first and last slides of the sequence, whereas those sections of the symmetry axis segments would be restricted to the slides in between. Thus, it is necessary to use more samples to contemplate, with the different techniques of histochemistry and staining, sections equivalent to all regions of the organ or tissue in order to give the desired number of repetitions. However, the use of a large number of samples leads to numerous disadvantages, such as the need for a larger number of samples available, besides the higher material consumption, higher contact with hazardous substances, unnecessary generation of toxic waste and greater time spent in the laboratory activities.

Thus, the present work had as objective the development of an optimized technique for distributing serial sections of biological material embedded in historesin. To this purpose, it was based on the strategy of sections distribution of a sample on the slides in such a way that each of the three sections rows represented a distinct sample segment. The slides must be properly cleaned with sulphochromic solution ${ }^{4}$ and stored in ethanol $95 \% 5$, in order to prevent hydrophobic regions formation on the slide, which would make it difficult to build a thin layer of water to accommodate and distend the sections ${ }^{3}$. This can be done by means of a row of elliptical (Fig. 1 E) or rectilinear (Fig. 1 F) drops of water. When filling a section row, the slide should be immediately heated in a hot plate at about $60^{\circ} \mathrm{C}$ for water evaporation and adhesion of the section on slide. 


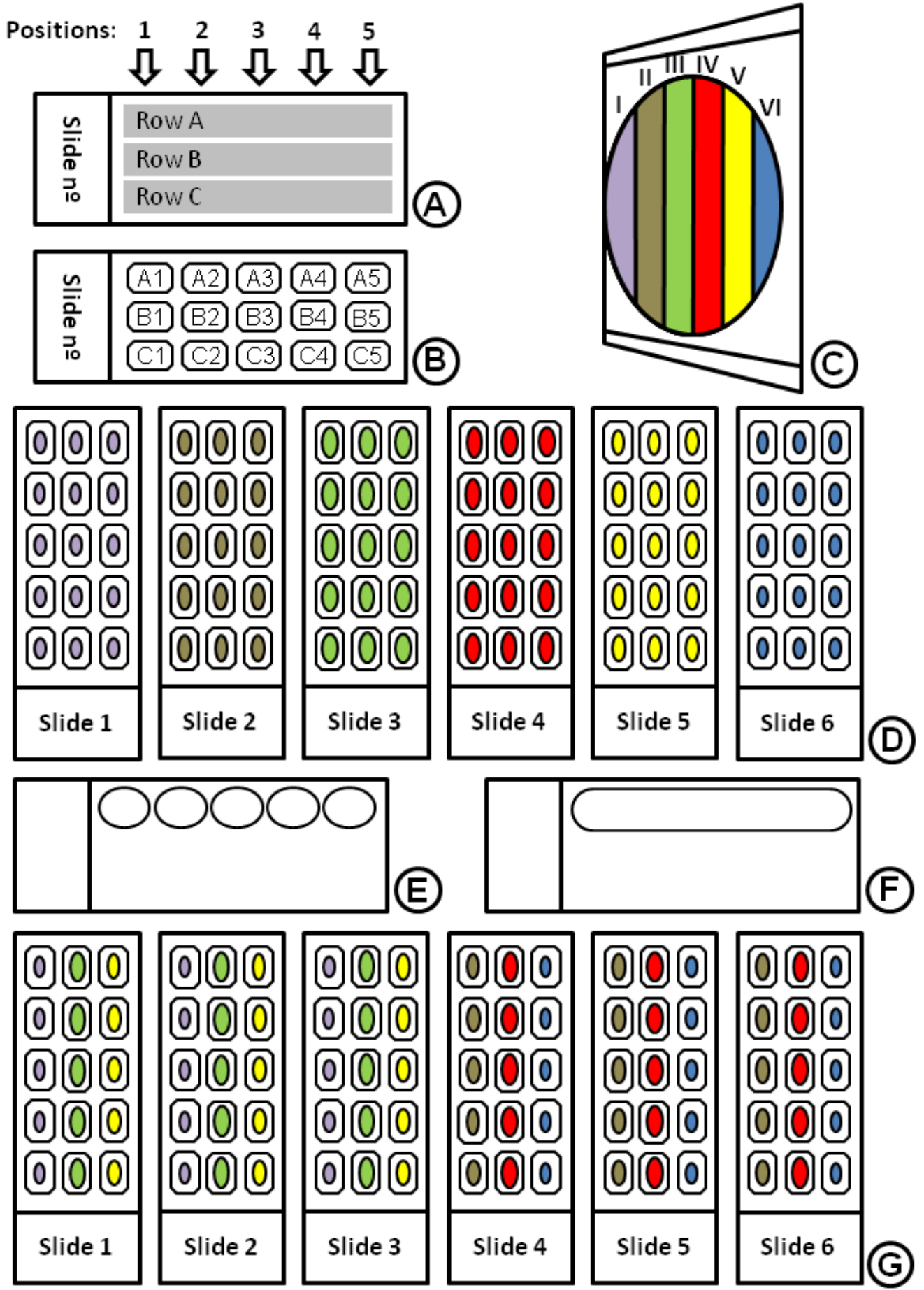

Figure 1. Schematics of the serial sections disposal of a sample included in historesin. A- Slide illustrating the criteria for the sections arrangement. B- Slide containing 15 sections with their respective coordinates. C- Historesin block in side view, containing a fusiform sample positioned in order to obtain longitudinal sections. The sample is divided into segments (I to VI), each one possessing a different color. These colors correspond to those shown in the sections in the slide sets in D and G. D- A 6 slides set containing serial sections obtained from the sample in C, in the traditional arrangement, where each slide has the sections of a single segment. E- Histological slide containing five elliptical drops of water in row A. There will be placed a section on each drop. F- Same as in E, but with a rectilinear drop of water for the accommodation of the five sections. G- A 6 slides set containing the sections obtained from the sample shown in $\mathrm{C}$, in an optimized arrangement. In this case, the rows $\mathrm{A}, \mathrm{B}$ and $\mathrm{C}$ of the slides 1-3 contain the sections of the segments I, III and V, respectively; whereas on the slides 4-6 these same rows contain the sections of the segments II, IV and VI, respectively. 
In the example of Figure $1 \mathrm{C}$, where the sample sectioning yields a set of six slides, sections in row A of each slide would be the firsts to be added, starting on slide 1. After adding the sections in row A of all slides, proceed in the same way for rows B and C. Thus, in the example of the 6 slides set, the slides 1 to 3 will contain sections of the sample segments I, III and V in rows A, B and C, respectively, while in slides 4 to 6 they will have segments II, IV and VI in the aforementioned rows (Fig. $1 \mathrm{G}$ ). In other words, considering the example of a radially or bilaterally symmetrical organ longitudinally sectioned, all the slides will contain tangential, intermediate, and radial sections. In the case of transverse sections, all the slides would contain sections from the proximal, middle and distal segments.

Obviously, the larger the number of sections obtained from a sample, the greater the slide set and consequently the first and last slides will not have the section of the most central segment, nor will the intermediate slides have the section of the more peripheral segments of the sample. Even so, a larger number of slides will contain sections from each segment of the sample, with three distinct segments per slide, which will certainly optimize the work. Although the distribution of serial sections in historesin slide set has already been discussed, this principle also applies to sections of paraffin embedded material, provided that it can properly accommodate at least two rectilinear ribbons per slide.

The elaboration of the present work was another initiative aimed at working with science in an optimized, economic, accessible and ecologically conscious way ${ }^{6-13}$.

\section{ACKNOWLEDGEMENTS}

I acknowledge the Fundação de Amparo à Pesquisa do Estado da Bahia - FAPESB for financial support, and the biologist Valdir Carvalho Ribeiro for English revision.

\section{REFERENCES}

1. Rohde Jr CJ. Serial sections from plastic-embedded specimens: arthropods in methacrylate. Stain Technol. 1965; 40: 43-44.

2. Ruzin SE. Plant microtechnique and microscopy. 1st ed. New York: Academic Press; 1999.

3. Berlyn GP, Miksche JP. Botanical microtechnique and cytochemistry. 1st. ed. Ames: Iowa State University Press; 1976.

4. Purvis MJ, Collier DC, Walls D. Laboratory techniques in botany. 1st ed. London: Butterworths; 1964.

5. Kraus JE, Arduin M. Manual básico de métodos em morfologia vegetal. 1st ed. Seropédica: Editora Universidade Rural; 1997.

6. Jordão LR, Takaki M. An efficient microbiological hood. Arq Biol Tecnol. 1986; 29: 297 299.

7. Takaki M. An eppendorf centrifuge with a blendor. Arq Biol Tecnol. 1987; 30: 633-634.

8. Paiva JGA, Frank-de-Carvalho SM, Magalhães MP, Graciano-Ribeiro D. Verniz vitral incolor $500^{\circledR}$ : uma alternativa de meio de montagem economicamente viável. Acta Bot Bras. 2006; 20: 257-264.

9. Leitão CAE, Cortelazzo AL. An inexpensive alternative equipment for the plant material embedding in the paraffin under the vacuum. Braz. Arch. Biol. Technol. 2008; 51: 10111014.

10. Marinho LC, Leitão CAE. Herborization hot chamber set upon a steel stand: a low-cost alternative for laboratories in developing. Rev Biociênc. 2015; 20: 32-39.

11. Leitão CAE. Chapa aquecedora artesanal para secagem de meio de montagem de lâminas permanentes. Genét Esc. 2015; 10: 170-175.

12. Leitão CAE. 2016. An alternative stage micrometer for use at light microscope. Perspec Ci Tecnol. 2016; 8: 58-61.

13. Marinho LC, Takiya C, Leitão CAE. Polarizing filters installation in biological microscope using recycled material. Perspec Ci Tecnol. 2016; 8: 29-34. 
Received: February 24, 2018; Accepted: June 04, 2018 